\title{
Intraocular penetration of the antibiotic Fucidin
}

\author{
A. J. GHADWIGK AND B. JAGKSON \\ Manchester
}

The steroid antibiotic Fucidin, or sodium fusidate, has been in use for a number of years a $\frac{\overline{0}}{\mathrm{a}}$ an antistaphylococcal agent. It has been used empirically in the treatment of intraoculach staphylococcal infection, but there has been no study of the degrees of penetration of the drug into the aqueous humour in the normal intact human eye, and the present study was therefore undertaken to investigate this phenomenon.

\section{Methods}

General Patients were admitted for routine cataract extraction 3 days preoperatively. It was decided to exclude all cases from the series that were abnormal in any way. Thus no diabetics werfo included, nor any cases where the cataracts were secondary to old uveitis or to glaucoma. Sodium 6 fusidate was given in a dosage of $500 \mathrm{mg}$. (2 capsules) three times a day before meals for the 3 pre응 operative days. Some patients experienced nausea and in two vomiting occurred on the first days only. No other side-effects were noted. Immediately preoperatively $5 \mathrm{ml}$. venous blood was takerp for the estimation of serum concentrations. The patients were prepared for cataract extractiong under local anaesthesia in the usual way. In order to ensure that the sample of aqueous to be takerp was not contaminated, a new method of abstracting it from the anterior chamber was devised.

Aspiration of aqueous humour (A.F.C.) A large flap of conjunctiva and Tenon's capsule was prepared above the superior limbus. This was then dissected down to the limbus and the dissection continued into the cornea. The cornea was split as in a trephine operation for about $3 \mathrm{~mm}$. down from thछ limbus, thus entering the avascular area beyond the peripheral capillary loops. Haemostasis havinge been achieved, the anterior chamber was entered by a small stab incision through this avascular zone: The aqueous was aspirated through an air needle. This method ensured that a good volume of fluidé was obtained, approximately $0 \cdot 2-0 \cdot 3 \mathrm{ml}$, and that it was uncontaminated. The samples were then immediately used in the assay. After the aspiration of aqueous, the anterior chamber was re-formed with sterile saline and the operation continued. In all the patients the extractions were uneventfu䟠 and no postoperative complications ensued.

Biological assay $(B . \mathcal{F}$ ) Sodium fusidate assays were made by an agar plate diffusion method using Corynebacterium xerosis (Leo strain $\mathrm{FF}(\mathrm{M})$ ), which was found to be suitable for the purpose. Thণ్ media employed were those suggested by the Biological Department of Leo Pharmaceutical Products (Laboratory notes, May, 1964). The method used was similar, except that $0 \cdot 1 \mathrm{ml}$. of an I8-hour culture of the test organism was inoculated into ro ml. melted medium stored in individual containers

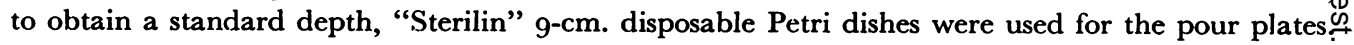
Disks measuring $6 \mathrm{~mm}$. in diameter were cut out of Ford's 428 Mill blotting paper and placed on the surface of the medium; a standard 3-mm. loop was used to transfer the test fluid to each disk because of the small amount of intraocular fluid available. Comparison between the test anc control plates after incubation at $37^{\circ} \mathrm{C}$. for 18 hours enabled the amount of sodium fusidate presen $\mathbb{Q}$ to be determined. 


\section{Results}

These are given in the Table. The eighteen patients were investigated and are shown in the first column. The next columns show the concentrations of sodium fusidate in the serum and in the aqueous humour.

Table Results in eighteen cases

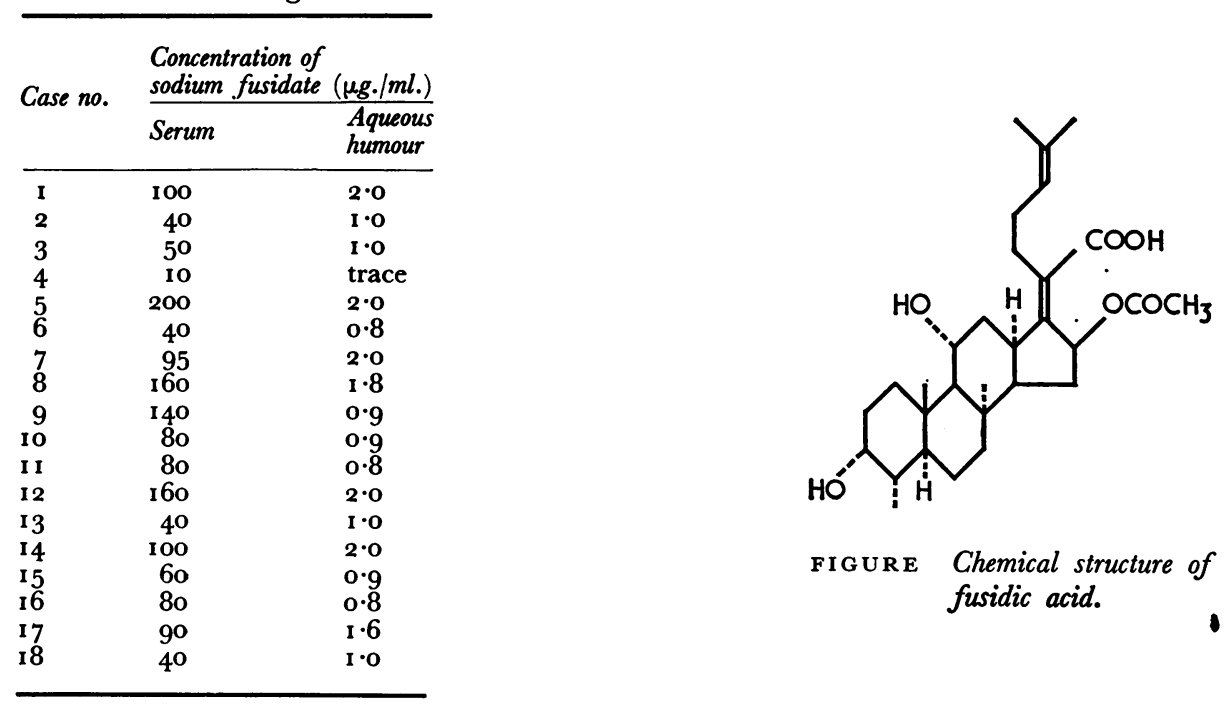

\section{Discussion}

A persistent problem in ocular therapeutics is the achievement of adequate levels of antibacterial substances in the intraocular fluid. The antibiotic which passes into the aqueous humour most readily is chloramphenicol (Leopold, Nichols, and Vogel, 1950). It has a small molecular size and is fat-soluble and hence passes the blood-aqueous barrier well. Absorption also occurs readily through the cornea from locally applied solutions. Its main disadvantages are its toxicity when given systemically and its limited range of antibacterial activity. The other antibiotics commonly used pass poorly into the aqueous humour, and some cause local sensitivity.

Three compounds have been isolated which are steroid-like antibiotics. These are helvolic acid (Ghain, Florey, Jennings, and Williams, 1943), cephalosporin Pl (Burton and Abraham, I95I), and fusidic acid. This last was isolated by Godtfredsen, Jahnsen, Lorck, Roholt, and Tybring ( 1962 ) from the fungus Fucidium coccineum; it is the most active of the group and is used as the sodium salt, which is water-soluble. Its structure is shown in the Figure (above).

Although it bears a superficial resemblance to the hormonal steroids, stereochemically it is fundamentally different (Arigoni, Daehne, Godtfredsen, Melera, and Vangedal, I964).

Its main therapeutic use is as an antistaphylococcal antibiotic, and it has been shown to inhibit the growth of most strains of Staphylococcus aureus, including penicillin-resistant strains, in a concentration as low as $0 \cdot 1 \mu \mathrm{g} . / \mathrm{ml}$. (Brit. med. $7 ., 1962$ ). It has been in use 
for 5 years, and no toxicity pattern has emerged. After the standard oral dosage, serum

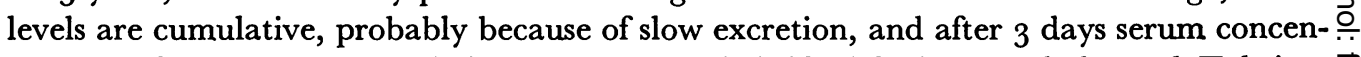
trations of up to $100 \mu \mathrm{g} . / \mathrm{ml}$. have been recorded (Godtfredsen, Roholt, and Tybring, $\overrightarrow{\vec{F}}$ 1962).

Sodium fusidate has two biophysical properties which make a theoretical assessment of its degree of penetrance into the eye very difficult: it shows strong surface activity and it $\frac{\bar{s}}{\sigma}$ is fat-soluble. Stewart (1964) has concluded that these properties facilitate diffusion $\stackrel{\odot}{\circ}$ between aqueous and lipid phases and hence passage across biochemical barriers. On the other hand, like many antibiotics, it is bound to serum proteins. In the normal eye the $\vec{O}$ aqueous humour is virtually protein-free, and this might be expected to be a factor inhibiting access to the anterior chamber.

With regard to our findings, the serum concentrations accord with those found by other $\frac{0}{0}$. authors (Godtfredsen and others, I962; Hierholzer, Knothe, Rehn, and Koch, 1966). ఝ This is a useful confirmation that our patients are a uniform group, and that our assay $\overrightarrow{\mathrm{N}}$ method is accurate.

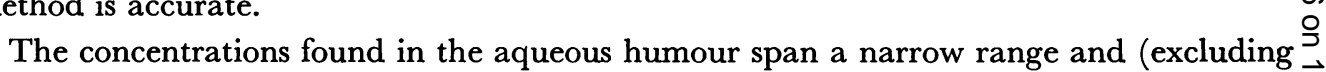
Case 4) vary from $0 \cdot 8$ to $2 \cdot 0 \mu \mathrm{g} . / \mathrm{ml}$. (mean $\mathrm{I} \cdot 3$ ). Case 4 is rather peculiar and we suspect that he did not take all his capsules; he was an odd character, and the staff tell us that they often found him secreting medicaments about his person to avoid taking them.ฏ Possibly he should be excluded from the series.

As a result of these findings we concluded that, in patients given a full systemic thera- 8 peutic dose, sodium fusidate passes into the aqueous humour of the quiet eye in effective concentrations, and could thus be used as a prophylactic antibiotic.

It is to be expected that, in an inflamed eye, the concentrations in the aqueous will be much higher than we have found. This is due to the high protein content in such circum- $\stackrel{\circ}{\Phi}$ stances which should cause the sodium fusidate concentration to rise because of the protein- $\stackrel{\Omega}{\Rightarrow}$ binding effect.

We hope to do further work to see if this is the case.

Finally, we should like to record a purely clinical impression. One of us had an opportunity to use sodium fusidate in intraocular staphylococcal infections before the start of this series, and feels very strongly that it works very well and is a very valuable antibiotic in such circumstances. The drug must be used systemically as local application causes excessive stinging.

\section{Summary}

(I) A series is described in which patients having routine cataract extractions were given the antibiotic sodium fusidate preoperatively, after which assays were taken of its concentrations in the serum and aqueous humour.

(2) The results show that, in the quiet eye, this drug passes the blood-aqueous barrier in therapeutic concentrations.

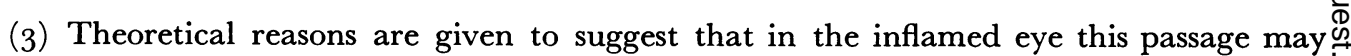
be enhanced.

Our thanks are due to Mr. P. L. Blaxter for permission to work on his cases, to our technician, Mr. E. G. Miller, for much of the work on the assays, and to Mr. P. N. Underwood, of Leo Laboratories Ltd., for his $\triangle$ help and advice. 


\section{References}

ARIgONI, D., DAEHNe, W. von, GodTfredsen, w. o., Melera, A., and VANGedAl, s. (1964) Experientia (Basel), 20, 344

BURTON, H. S., and ABRAHAM, E. P. (195I) Biochem. 7., 50, 168

chain, E., florey, H. W., Jennings, m. A., and williams, t. I. (1943) Brit. F. exp. Path., 24 , 108 gODTfRedsen, W. O., JAhNSEN, s., LORCK, H., ROHOlt, K., and TYBRING, L. (ig62) Nature (Lond.), r93, 987 , ROHOLT, K., and TYBRING, L. (1962) Lancet, I, 928 hierholzer, G., KNOthe, H., ReHN, J., and коch, F. (1966) Arzneimittel-Forsch., I6, I549 LEO PHARMACEUTICAL PRODUCTS (1964) Laboratory Notes, May, ig64 LEOPOLD, I. H., Nichols, A. G., and VOGEL, A. W. (1950) Arch. Ophthal. (Chicago), 44, 22 STEWART, G. T. (1964) Pharmakotherapia, 2, No. I, p. 137

“TO-DAY'S DRUGs" (I962) Brit. med. J., 2, I I 88 